\title{
Epidermal growth factor receptor exon 20 p.S768I mutation in non-small cell lung carcinoma: A case report combined with a review of the literature and investigation of clinical significance
}

\author{
GIUSEPPINA IMPROTA ${ }^{1}$, ANGELA PETTINATO ${ }^{2}$, STEFANIA GIERI ${ }^{3}$, GIUSEPPA SCANDURRA ${ }^{4}$, \\ WOJCIECH SKOVRIDER-RUMINSKI ${ }^{5}$, ESTRID HøGDALL ${ }^{5}$ and FILIPPO FRAGGETTA ${ }^{2}$ \\ ${ }^{1}$ Laboratory of Clinical Research and Advanced Diagnostics, Cancer Referral Centre of Basilicata, \\ National Institute for Research and Treatment, Rionero in Vulture, Potenza I-85028; ${ }^{2}$ Pathology Unit, Cannizzaro Hospital, \\ Catania I-95126; ${ }^{3}$ Laboratory of Oncologic Technologies, Institute of Bioimaging and Molecular Physiology, \\ National Research Council, Cefalù, Palermo I-90015; ${ }^{4}$ Oncology Unit, Cannizzaro Hospital, Catania I-95126, Italy; \\ ${ }^{5}$ Molecular Unit, Pathology Department, Herlev Hospital, Herlev 2730, Denmark
}

Received January 14, 2015; Accepted September 9, 2015

DOI: $10.3892 / \mathrm{ol} .2015 .3863$

\begin{abstract}
Epidermal growth factor receptor (EGFR) plays a significant role in non-small cell lung cancer (NSCLC), the most prevalent form of lung cancer worldwide. Therefore, EGFR may be a useful molecular target for personalized therapy utilizing tyrosine kinase inhibitors (TKIs). Somatic activating EGFR mutations may be used to identify tumors sensitive to the effects of small-molecule EGFR-TKIs (gefitinib and erlotinib), and alternative, less frequently observed mutations, including the majority of mutations identified within exon 20, may be associated with a lack of response to TKIs. However, due to the comparative rarity of EGFR exon 20 mutations, clinical information concerning the association between EGFR exon 20 mutations and responsiveness to TKIs has been limited within the relevant literature, particularly for certain rare mutations, including p.S768I. The current study reports the case of a patient with NSCLC harboring a p.S768I mutation in the EGFR gene [a substitution at codon 768 of exon 20 (c.2303G $>$ T, p.S768I)], as well as a mutation at codon 719, exon 18 (p.G719A). The relevant literature concerning this rare EGFR somatic mutation is also reviewed.
\end{abstract}

\section{Introduction}

Lung cancer is the most common cause of cancer-associated mortality in a number of developed countries (1), and non-small cell lung cancer (NSCLC) is the most prevalent

Correspondence to: Dr Giuseppina Improta, Laboratory of Clinical Research and Advanced Diagnostics, Cancer Referral Centre of Basilicata, National Institute for Research and Treatment, 1 Padre Pio Street, Rionero in Vulture, Potenza I-85028, Italy

E-mail: giuseppina.improta@gmail.com

Key words: p.S768I mutation, epidermal growth factor receptor, tyrosine kinase inhibitors, gefitinib, lung adenocarcinoma form of lung cancer worldwide, accounting for $85 \%$ of all lung cancer cases $(2,3)$. Epidermal growth factor receptor (EGFR) may play a significant role in NSCLC, and is thus a potential molecular target for personalized therapy with tyrosine kinase inhibitors (TKIs) (4).

Somatic activating EGFR mutations, which are clustered within the tyrosine kinase domain, most commonly occur in the form of deletions in exon 19 or p.L858R mutations in exon 21 . These somatic activating mutations account for $\sim 85 \%$ of all EGFR mutations, and may indicate the likely sensitivity of tumors to the effects of small-molecule inhibitors (such as gefitinib and erlotinib) (4-6). Other, less prevalent EGFR mutations, including exon 18 p.G719X mutations (3\% of all EGFR mutations) (7) and exon 21 p.L861Q (2\% of all EGFR mutations) have been associated with enhanced efficacy of EGFR-TKIs (8). By contrast, alternative classes of EGFR mutations may be associated with a lack of response to TKIs, and this is the case for the majority of exon 20 mutations, which account for $\sim 5 \%$ of all EGFR mutations (9).

EGFR exon 20 mutations occur in patients with clinicopathological features similar to those of patients with classical EGFR mutations (women, non-smokers, adenocarcinomas). Exon 20 mutations encompass the area surrounding amino acid positions Glu762 to Cys775, located in the N-lobe of the kinase domain of EGFR following the C-helix. These mutations induce a pattern of in vitro and in vivo resistance to EGFR-TKIs (9). A number of mutations in EGFR exon 20 are thought to increase the affinity of EGFR for adenosine triphosphate (ATP), thus decreasing the efficacy of TKI inhibition (10). However, due to the comparative rarity of $E G F R$ exon 20 mutations, clinical data concerning the association between EGFR exon 20 mutations and responsiveness to TKIs has, to the best of our knowledge, been limited so far within the relevant literature, particularly for certain rare mutations, including p.S768I.

The present study reports the case of a patient with NSCLC exhibiting p.S768I in the EGFR gene [a substitution at codon 768 of exon 20 (c.2303G>T, p.S768I)], as well as a 

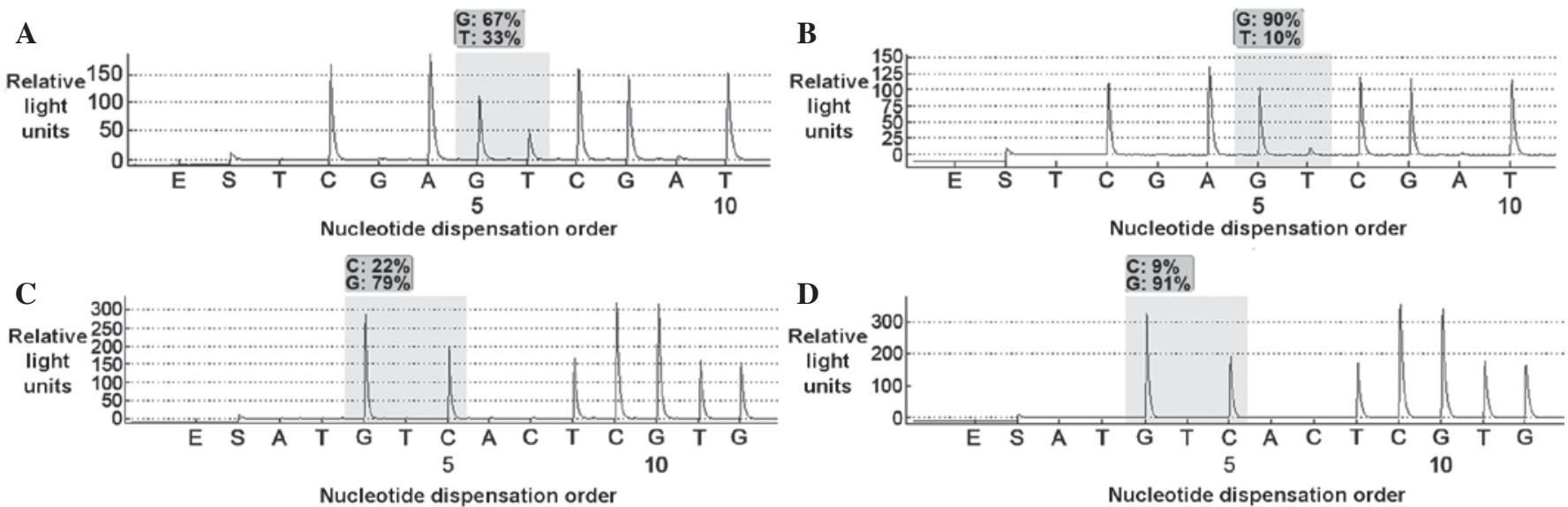

Figure 1. Pyrogram traces obtained following histological and cytological analyses of samples. (A) Pyrogram trace obtained following analysis of the histological sample from the metastatic supraclavicular lymph node, revealing an AGC $>$ ATC mutation (p.S768I) in the second base of codon 768 of $E G F R$ exon 20 (allele frequency, 33\%). (B) Pyrogram trace obtained following analysis of the cytological sample from pericardial effusion, revealing an AGC $>$ ATC mutation (p.S768I) in the second base of codon 768 of EGFR exon 20 (allele frequency, 10\%). (C) Pyrogram trace obtained following analysis of the histological sample from the metastatic supraclavicular lymph node, revealing a GGC $>$ GCC mutation (p.G719A) in the second base of codon 719 of EGFR exon 18 (allele frequency, 22\%). (D) Pyrogram trace obtained following analysis of the cytological sample from pericardial effusion, revealing a GGC $>$ GCC mutation (p.G719A) in the second base of codon 719 of EGFR exon 18 (allele frequency, 9\%). EGFR, epidermal growth factor receptor.

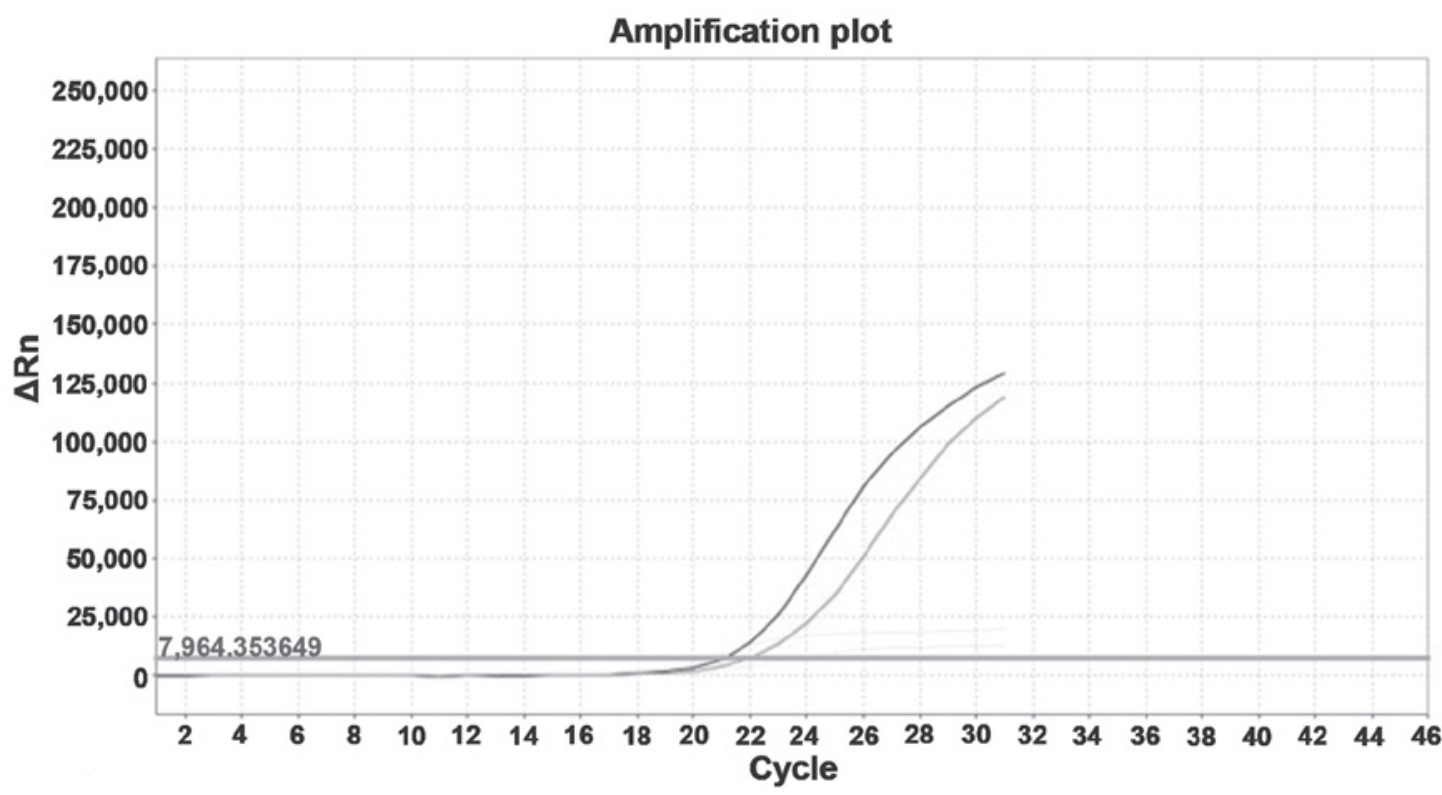

Figure 2. Magnitude of normalized fluorescence signal generated by the reporter at each cycle during polymerase chain reaction amplification of the histological sample from the metastatic supraclavicular lymph node. The ADx-amplification refractory mutation system was used to reveal synchronous mutations at codon 719 of exon 18 (p.G719A) and at codon 768 of exon 20 (p.S768I). $\Delta$ Rn, baseline-corrected normalized reporter.

mutation at codon 719, exon 18 (p.G719A), in combination with a review of the relevant literature regarding this rare $E G F R$ somatic mutation.

\section{Case report}

A 48-year-old Asian male was admitted to Cannizzaro Hospital (Catania, Italy) in March 2014, presenting with a poor performance status (PS) and increasing dyspnea. A total body computed tomography (CT) scan revealed a neoformation at the base of the left lung, measuring $\sim 4 \mathrm{~cm}$ and extending to the visceral pleura. Furthermore, additional secondary nodules in both lungs, along with pericardial effusion, were identified.
Mediastinal lymphadenopathy and liver metastases were detected. The patient underwent a CT-guided biopsy of the left basal pulmonary lesion, which exhibited the typical histology of an adenocarcinoma, according to well-established World Health Organization criteria (11). The neoplasia consisted of neoplastic glands with focal papillary structures. Immunoreactivity for thyroid transcription factor-1 and napsin A, and negativity for thyroglobulin supported the pulmonary origin of the lesion.

Written informed consent was obtained from the patient for sequencing of the EGFR gene and for publication of the case report. The PyroMark Q24 system (Qiagen GmbH, Hilden, Germany) was utilized for pyrosequencing analysis of EGFR exons $18-21$, using $2.5-\mu \mathrm{m}$ sections of formalin 
A
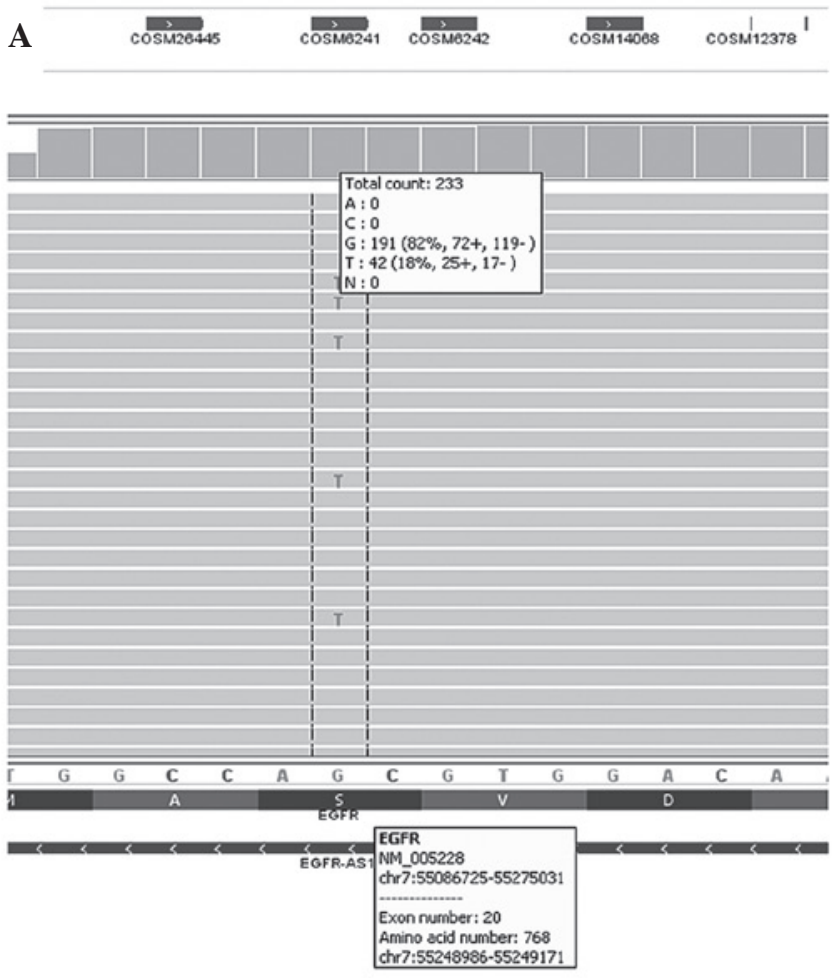

B

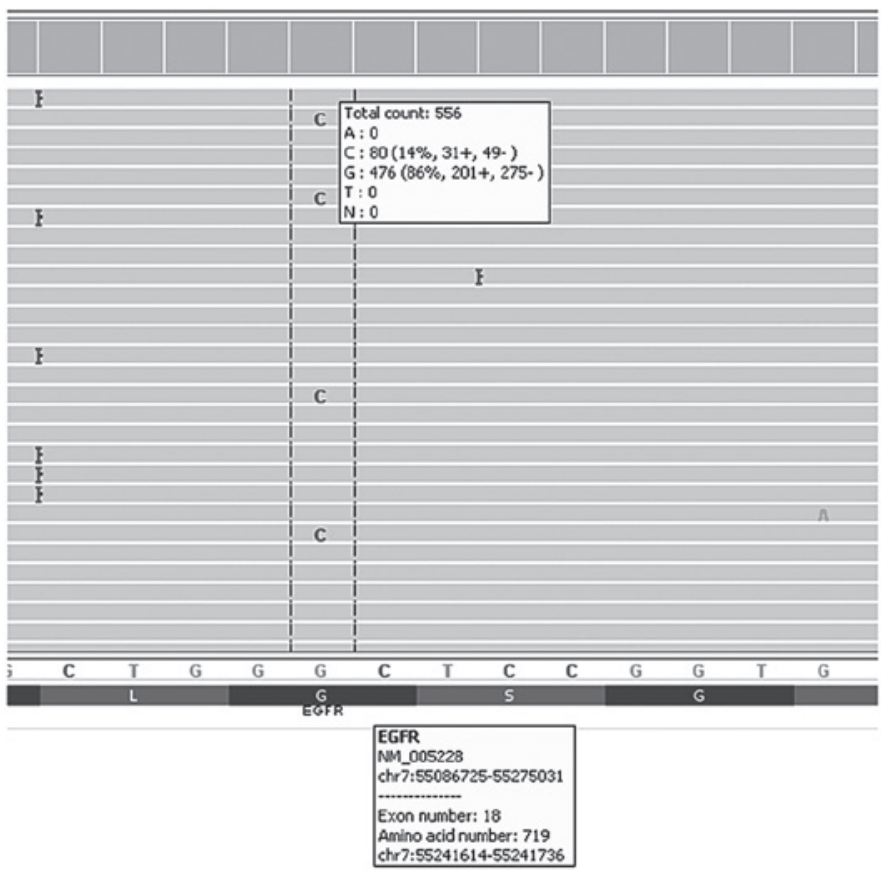

Figure 3. Next-generation sequencing trace obtained using an Ion Torrent ${ }^{\mathrm{TM}}$ approach, revealing the coexistence of (A) p.S768I and (B) p.G719A mutations, in epidermal growth factor receptor exons 20 and 18 , respectively.

fixed paraffin-embedded tissue from metastatic supraclavicular lymph nodes (whole slide) and thinPrep cytological samples from pericardial effusion. All slides underwent genomic DNA extraction, using QIAamp MinElute spin columns (Qiagen $\mathrm{GmbH}$ ), according to the manufacturer's instructions, and the sequence of interest was amplified by polymerase chain reaction (PCR; Applied Biosystems GeneAmp ${ }^{\circledR}$ PCR System 9700; Thermo Fisher Scientific, Inc., Foster City, CA, USA). Using a therascreen EGFR Pyro kit (Qiagen $\mathrm{GmbH}$ ), all hotspot regions (4) of exons of the EGFR gene were analyzed, and PyroMark Q24 software (Qiagen, $\mathrm{GmbH}$ ) was utilized for data analysis.

Pyrosequencing analysis of the full exome of EGFR from each sample type, revealed the presence of a rare mutation at codon 768, exon 20 (p.S768I; Fig. 1A and B), as well as a mutation at codon 719, exon 18 (p.G719A; Fig. 1C and D).

Patient DNA was subsequently retested for the presence of a p.S768I mutation in exon 20 of the EGFR gene, and its association with a mutation at codon 719, exon 18 (p.G719A). Molecular results were confirmed using the AmoyDx EGFR Mutation Test kit (Amoy Diagnostics Co.Ltd., Xiamen, China) for the detection of somatic mutations in the EGFR gene, using the principle of amplified refractory mutation. The assay was performed according to the manufacturer's instructions, using the Applied Biosystems StepOnePlus ${ }^{\mathrm{TM}}$ Real-Time PCR system (Thermo Fisher Scientific, Inc.; Fig. 2).

Patient DNA was additionally analyzed using next generation sequencing on an Ion Torrent ${ }^{\mathrm{TM}}$ with Applied Biosystems Colon-Lung v2 panel (Thermo Fisher Scientific, Inc.). This analysis identified two mutations: EGFR (c.2303G $>$ T, p.S768I) with a target coverage depth of 233 in exon 20, and EGFR
(c.2156G $>$ C, p.G719A) in exon 18 with a target coverage depth of 556 (Fig. 3).

Due to conflicting data in the existing literature regarding the effectiveness of EGFR-TKIs in the presence of a p.S768I mutation, and due to the poor PS of the patient, a decision was reached to administer the patient with supportive care only. The patient succumbed to the disease 6 weeks subsequent to diagnosis.

\section{Discussion}

EGFR mutations are considered to be a robust predictive biomarker of clinical response to EGFR-TKIs in clinical practice (4). Gefitinib, an EGFR-targeting agent, is an orally active small molecule drug, which has been demonstrated to exhibit antitumor activity in NSCLC. The response of NSCLC to gefitinib has been closely associated with EGFR mutations in the kinase domain (4,5); Lynch et al (4) suggested that repositioning of critical residues due to such mutations may act to stabilize their interaction with ATP and with gefitinib (its competitive inhibitor), and gefitinib-induced inhibition may thus be enhanced by certain mutations. However, as EGFR mutations may occur at varying positions within the kinase domain, the biochemical properties of these mutations and the sensitivity to gefitinib of tumors possessing rare mutations may not be identical (4). Therefore, the association between EGFR mutations and sensitivity to EGFR-TKIs in NSCLCs remains controversial, particularly for rare mutations (4-6,7,12-17).

The p.S768I mutation in exon 20 of the EGFR gene is a rare mutation that has been identified sporadically in previous studies and is reported to confer reduced sensitivity to gefitinib in vitro compared with the two most commonly 
Table I. Summary of review of the literature concerning the p.S768I mutation, as well as its associated mutations at alternative EGFR codons.

\begin{tabular}{|c|c|c|c|c|c|c|c|}
\hline Author (reference no.) & Year & Nationality & $\begin{array}{l}\text { Patients, } \\
\text { n }\end{array}$ & $\begin{array}{c}E G F R \\
\text { mutants, } \\
\mathrm{n}\end{array}$ & $\begin{array}{c}\text { p.S768I } \\
\text { mutants, } \\
\mathrm{n}\end{array}$ & $\begin{array}{l}\text { Reported } \\
\text { mutations }\end{array}$ & RECIST \\
\hline Huang et al (13) & 2004 & Taiwanese & 101 & 39 & $\begin{array}{l}1 \\
1\end{array}$ & $\begin{array}{l}\text { S768I+G719C } \\
\text { S768I+G719S }\end{array}$ & \\
\hline Kosaka et al (12) & 2004 & Japanese & 277 & 111 & 1 & S768I+V769L & \\
\hline Shigematsu et al (7) & 2005 & $\begin{array}{l}\text { Japanese, } \\
\text { Taiwanese, } \\
\text { Australian }\end{array}$ & 617 & 134 & 1 & S768I+G719S & \\
\hline Takano et al (31) & 2005 & Japanese & 66 & 43 & $\begin{array}{l}1 \\
1\end{array}$ & $\begin{array}{l}\text { S768I+L858R } \\
\text { S768I+G719C }\end{array}$ & \\
\hline Asahina et al (27) & 2006 & Japanese & 1 & 1 & 1 & S768I+V769L & PD \\
\hline Pugh et al (23) & 2007 & Japanese & 349 & 102 & $\begin{array}{l}2 \\
1 \\
1\end{array}$ & $\begin{array}{c}\text { S768I } \\
\text { S768I+V769L } \\
\text { S768I+V774M }\end{array}$ & \\
\hline & & Asian & 39 & 8 & 1 & S768I & PR \\
\hline Wu et al (20) & 2008 & Taiwanese & 515 & 253 & $\begin{array}{l}1 \\
1\end{array}$ & $\begin{array}{l}\text { S768I+G719A } \\
\text { S768I+L858R }\end{array}$ & $\begin{array}{l}\text { PD } \\
\text { PR }\end{array}$ \\
\hline Masago et al (25) & 2010 & Japanese & 1 & 1 & 1 & S768I & PR \\
\hline Wu et al (8) & 2011 & Taiwanese & 1,261 & 627 & 2 & S768I+L858R & PR \\
\hline $\begin{array}{l}\text { Szumera-Ciećkiewicz } \\
\text { et al (26) }\end{array}$ & 2013 & Polish & 273 & 29 & 1 & S768I & \\
\hline Kobayashi et al (29) & 2013 & Japanese & 79 & 11 & $\begin{array}{l}2 \\
1\end{array}$ & $\begin{array}{l}\text { S768I+G719A } \\
\text { S768I+V769L }\end{array}$ & $\begin{array}{l}\text { PR } \\
\text { PR }\end{array}$ \\
\hline Weber et al (24) & 2014 & Danish & 462 & 57 & 1 & S768I & PD \\
\hline Pallan et al (28) & 2014 & British & 2 & 2 & 2 & S768I & PD \\
\hline
\end{tabular}

EGFR, epidermal growth factor receptor; RECIST, Response Evaluation Criteria In Solid Tumors (37); PR, partial response; PD, progressive disease.

observed types of mutations: Exon 19 deletions and p.L858R mutations $(18,19)$. Due to the relative rarity of EGFR exon 20 mutations, clinical data concerning their associations with drug responsiveness are limited, and conflicting data exist regarding the sensitivity to EGFR-TKIs of tumors harboring p.S768I mutations $(20,21)$. The literature review conducted for the present report revealed a limited number of cases involving p.S768I mutations (Table I), and conflicting data with regard to its clinical association with EGFR-TKI efficacy. A notable observation, which was confirmed by the results of the present study, is the association between p.S768I in exon 20 and other EGFR mutations, identified frequently in exon 18 and 21 (22). The significance of this molecular/mutational association remains to be elucidated, and may require further investigation. In previous studies where this molecular/mutational association was not observed (23-26), there may have been a lack of utilization of sensitive detection techniques such as next-generation sequencing approaches.

As shown in Table I, Asahina et al (27) reported that p.S768I and p.V769L mutations were associated with insensitivity to EGFR-TKIs in the patient cohort investigated. In a Danish patient cohort investigated by Weber et al (24), one patient possessed a p.S768I point mutation in exon 20. This patient exhibited no response to treatment with the EGFR-TKI erlotinib, and succumbed to progressive disease 4 weeks subsequent to the start of treatment. An additional case concerning a Taiwanese patient with progressive disease and harboring two distinct mutations (p.S768I and p.G719A), was identified by $\mathrm{Wu}$ et al (20), and an a further two cases were reported by Pallan et al (28). By contrast, a positive clinical response to gefitinib in an NSCLC patient harboring the rare mutation p.S768I was observed by Masago et al (25). Additional previous studies have also reported partial responses to EGFR-TKIs in patients exhibiting p.S768I and other mutations $(8,20,23,29,30)$. In addition, a number of retrospective analyses of $E G F R$ mutations (Table I) have investigated the p.S768I mutation; however, the clinical responsiveness to EGFR-TKIs has not been reported $(7,12,13,26,31)$.

In certain in vitro studies, a number of mutations have been shown to exhibit distinctive phosphorylation patterns in several C-terminal tyrosine (Tyr) residues of the EGFR gene, and have demonstrated varying sensitivities to gefitinib when stably transfected into NSCLC cell lines $(19,32)$. A number of these mutants, including p.S768I, are hyperphosphorylated on the Tyr 1045 residue, which is normally involved in the recruitment of Casitas B-lineage lymphoma 
(Cbl) to EGFR and the initiation of Cbl-mediated receptor multi-ubiquitination; mutations at this site are refractory to EGF-induced ubiquitination and degradation (33-35). Gefitinib treatment exerts reduced growth-suppressive effects on cells expressing exon 20 mutations compared with cells expressing exon 19 deletions or L858R mutations, or those expressing the wild-type counterpart (19).

Kancha et al (18) identified four sets of EGFR mutations based on their drug sensitivity profiles in vitro: i) mutations sensitive to all three drugs investigated (gefitinib, erlotinib and AEE788) with half maximal inhibitory concentration $\left(\mathrm{IC}_{50}\right)$ values in the low nanomolar range (L858R and Del 747-753 insS mutations); ii) mutations exhibiting reduced sensitivity to gefitinib $\left(\mathrm{IC}_{50}>100 \mathrm{nmol} / \mathrm{l}\right)$, but sensitivity $\left(\mathrm{IC}_{50}<100 \mathrm{nmol} / \mathrm{l}\right)$ to both erlotinib and AEE788 (G719S, V742A and R776C mutations); iii) mutations exhibiting reduced sensitivity to both gefitinib and erlotinib, but sensitivity to AEE788 (D761N, S768I, S748F, L838V and L861Q mutations); and iv) mutations resistant to all three drugs investigated (N826S and T790M mutations).

However, despite the in vitro results reported by Kancha et al (18), data regarding the clinical significance of all EGFR mutations in the literature are unavailable at present. This includes p.S768I and other relatively rare mutations, whose association with EGFR-TKIs remains to be elucidated. Although a number of mutations in exons 18-21 have been identified to be associated with EGFR-TKI resistance, only p.T790M is known for its clinical significance to primary TKI drug resistance. This resistance is caused by a conformational change in the ATP-binding pocket, which increases the affinity of EGFR for its natural substrate, and reduces its affinity for EGFR-TKIs (7,36).

Kancha et al (18) categorized p.S768I in exon 20 as a mutation that confers reduced sensitivity to the in vitro activity of gefitinib. The relevant literature indicates that this type of mutation is rare, and is associated with insensitivity to EGFR-TKIs in vitro and in vivo, as previously described by Asahina et al (27). However, conflicting results have also been reported regarding the in vivo sensitivity of p.S768I mutants to TKIs; Masago et al (25), for example, reported a case of a patient with NSCLC harboring the p.S768I mutation who demonstrated a good clinical response to gefitinib.

The present study reported a case of NSCLC harboring a rare EGFR somatic mutation, along with the conflicting data from the literature regarding the clinical significance of this mutation. In vitro results reported by Kancha et al (18) do not consider the 'impact and the influence' of the tumor microenvironment; it is not necessarily notable that the sensitivity to certain drugs in vitro differs from that observed in vivo. Thus, it may be speculated that the p.S768I mutation is drug sensitive.

In conclusion, further examination of the sensitivity of EGFR-TKIs in a more representative cohort of NSCLC patients harboring a range of rare mutations may be required in order to optimize the individual treatment of patients with such mutations.

\section{References}

1. Ferlay J, Soerjomataram I, Dikshit R, Eser S, Mathers C, Rebelo M, Parkin DM, Forman D and Bray F: Cancer incidence and mortality worldwide: Sources, methods and major patterns in GLOBOCAN 2012. Int J Cancer 136: E359-E386, 2015.
2. Jemal A, Siegel R, Ward E, Hao Y, Xu J, Murray T and Thun MJ: Cancer statistics, 2008. CA Cancer J Clin 58: 71-96, 2008.

3. Molina JR, Yang P, Cassivi SD, Schild SE and Adjei AA: Non-small cell lung cancer: Epidemiology, risk factors, treatment, and survivorship. Mayo Clin Proc 83: 584-594, 2008.

4. Lynch TJ, Bell DW, Sordella R, Gurubhagavatula S, Okimoto RA, Brannigan BW, Harris PL, Haserlat SM, Supko JG, Haluska FG, et al: Activating mutations in the epidermal growth factor receptor underlying responsiveness of non-small-cell lung cancer to gefitinib. N Engl J Med 350: 2129-2139, 2004

5. Paez JG, Jänne PA, Lee JC, Tracy S, Greulich H, Gabriel S, Herman P, Kaye FJ, Lindeman N, Boggon TJ, et al: EGFR mutations in lung cancer: Correlation with clinical response to gefitinib therapy. Science 304: 1497-1500, 2004.

6. Pao W, Miller V, Zakowski M, Doherty J, Politi K, Sarkaria I, Singh B, Heelan R, Rusch V, Fulton L, et al: EGF receptor gene mutations are common in lung cancers from 'never smokers' and are associated with sensitivity of tumors to gefitinib and erlotinib. Proc Natl Acad Sci USA 101: 13306-13311, 2004.

7. Shigematsu H, Lin L, Takahashi T, Nomura M, Suzuki M, Wistuba II, Fong KM, Lee H, Toyooka S, Shimizu N, et al: Clinical and biological features associated with epidermal growth factor receptor gene mutations in lung cancers. J Natl Cancer Inst 97: 339-346, 2005.

8. Wu JY, Yu CJ, Chang YC, Yang CH, Shih JY and Yang PC: Effectiveness of tyrosine kinase inhibitors on 'uncommon' epidermal growth factor receptor mutations of unknown clinical significance in non-small cell lung cancer. Clin Cancer Res 17: 3812-3821, 2011.

9. Yasuda H, Kobayashi S and Costa DB: EGFR exon 20 insertion mutations in non-small-cell lung cancer: Preclinical data and clinical implications. Lancet Oncol 13: e23-e31, 2012.

10. Yasuda H, Park E, Yun CH, Sng NJ, Lucena-Araujo AR, Yeo WL, Huberman MS, Cohen DW, Nakayama S, Ishioka K, et al: Structural, biochemical, and clinical characterization of epidermal growth factor receptor (EGFR) exon 20 insertion mutations in lung cancer. Sci Transl Med 5: 216ra177, 2013.

11. Travis WD, Brambilla E, Burke AP, Marx A and Nicholson AG (eds). Adenocarcinoma. In: WHO Classification of Tumours of the Lung, Pleura, Thymus and Heart. Vol 7. 4th edition. IARC Press, Lyon, pp26-37, 2015.

12. Kosaka T, Yatabe Y, Endoh H, Kuwano H, Takahashi T and Mitsudomi T: Mutations of the epidermal growth factor receptor gene in lung cancer: Biological and clinical implications. Cancer Res 64: 8919-8923, 2004.

13. Huang SF, Liu HP, Li LH, Ku YC, Fu YN, Tsai HY, Chen YT, Lin YF, Chang WC, Kuo HP, et al: High frequency of epidermal growth factor receptor mutations with complex patterns in non-small cell lung cancers related to gefitinib responsiveness in Taiwan. Clin Cancer Res 10: 8195-8203, 2004.

14. Tokumo M, Toyooka S, Kiura K, Shigematsu H, Tomii K, Aoe M, Ichimura K, Tsuda T, Yano M, Tsukuda K, et al: The relationship between epidermal growth factor receptor mutations and clinicopathologic features in non-small cell lung cancers. Clin Cancer Res 11: 1167-1173, 2005.

15. Han SW, Kim TY, Hwang PG, Jeong S, Kim J, Choi IS, Oh DY, Kim JH, Kim DW, Chung DH, et al: Predictive and prognostic impact of epidermal growth factor receptor mutation in non-small-cell lung cancer patients treated with gefitinib. J Clin Oncol 23: 2493-2501, 2005.

16. Mitsudomi T, Kosaka T, Endoh H, Horio Y, Hida T, Mori S, Hatooka S, Shinoda M, Takahashi T and Yatabe Y: Mutations of the epidermal growth factor receptor gene predict prolonged survival after gefitinib treatment in patients with non-small-cell lung cancer with postoperative recurrence. J Clin Oncol 23: 2513-2520, 2005.

17. Tsao MS, Sakurada A, Cutz JC, Zhu CQ, Kamel-Reid S, Squire J, Lorimer I, Zhang T, Liu N, Daneshmand M, et al: Erlotinib in lung cancer - molecular and clinical predictors of outcome. N Engl J Med 353: 133-144, 2005.

18. Kancha RK, von Bubnoff N, Peschel C and Duyster J: Functional analysis of epidermal growth factor receptor (EGFR) mutations and potential implications for EGFR targeted therapy. Clin Cancer Res 15: 460-467, 2009.

19. Chen YR, Fu YN, Lin CH, Yang ST, Hu SF, Chen YT, Tsai SF and Huang SF: Distinctive activation patterns in constitutively active and gefitinib-sensitive EGFR mutants. Oncogene 25: 1205-1215, 2006. 
20. Wu JY, Wu SG, Yang CH, Gow CH, Chang YL, Yu CJ, Shih JY and Yang PC: Lung cancer with epidermal growth factor receptor exon 20 mutations is associated with poor gefitinib treatment response. Clin Cancer Res 4: 4877-4882, 2008.

21. Beau-Faller M, Prim N, Ruppert AM, Nanni-Metéllus I, Lacave R, Lacroix L, Escande F, Lizard S, Pretet JL, Rouquette I, et al: Rare EGFR exon 18 and exon 20 mutations in non-small-cell lung cancer on 10117 patients: A multicentre observational study by the French ERMETIC-IFCT network. Ann Oncol 25: 126-131, 2014.

22. Shih JY, Gow CH and Yang PC: EGFR mutation conferring primary resistance to gefitinib in non-small-cell lung cancer. N Engl J Med 353: 207-208, 2005.

23. Pugh TJ, Bebb G, Barclay L, et al: Correlations of EGFR mutations and increases in EGFR and HER2 copy number to gefitinib response in a retrospective analysis of lung cancer patients. BMC Cancer 7: 128, 2007.

24. Weber B, Hager H, Sorensen BS, McCulloch T, Mellemgaard A Khalil AA, Nexo E and Meldgaard P: EGFR mutation frequency and effectiveness of erlotinib: A prospective observational study in Danish patients with non-small cell lung cancer. Lung Cancer 83: 224-230, 2014.

25. Masago K, Fujita S, Irisa K, Kim YH, Ichikawa M, Mio T and Mishima M: Good clinical response to gefitinib in a non-small cell lung cancer patient harboring a rare somatic epidermal growth factor gene point mutation; codon 768 AGC > ATC in exon 20 (S768I). Jpn J Clin Oncol 40: 1105-1109, 2010.

26. Szumera-Ciećkiewicz A, Olszewski WT, Tysarowski A, et al: EGFR mutation testing on cytological and histological samples in non-small cell lung cancer: A Polish, single institution study and systematic review of European incidence. Int J Clin Exp Pathol 6: 2800-2812, 2013.

27. AsahinaH,Yamazaki K, KinoshitaI, YokouchiH,Dosaka-AkitaH and Nishimura M: Non-responsiveness to gefitinib in a patient with lung adenocarcinoma having rare EGFR mutations S768I and V769L. Lung Cancer 54: 419-422, 2006

28. Pallan L, Taniere P and Koh P: Rare EGFR exon 20 S768I mutation predicts resistance to targeted therapy: A report of two cases. J Thorac Oncol 9: e75, 2014.
29. Kobayashi S, Canepa HM,Bailey AS, Nakayama S, Yamaguchi N, Goldstein MA, Huberman MS and Costa DB: Compound EGFR mutations and response to EGFR tyrosine kinase inhibitors. J Thorac Oncol 8: 45-51, 2013.

30. Han SW, Kim TY, Lee KH, et al: Clinical predictors versus epidermal growth factor receptor mutation in gefitinib-treated non-small-cell lung cancer patients. Lung Cancer 54: 201-207, 2006

31. Takano T, Ohe Y, Sakamoto H, et al: Epidermal growth factor receptor gene mutations and increased copy numbers predict gefitinib sensitivity in patients with recurrent non-small-cell lung cancer. J Clin Oncol 23: 6829-6837, 2005.

32. Greulich H, Chen TH, Feng W, Jänne PA, Alvarez JV, Zappaterra M, Bulmer SE, Frank DA, Hahn WC, Sellers WR and Meyerson M: Oncogenic transformation by inhibitor-sensitive and -resistant EGFR mutants. PLoS Med 2: e313, 2005.

33. Levkowitz G, Waterman H, Ettenberg SA, Katz M, Tsygankov AY, Alroy I, Lavi S, Iwai K, Reiss Y, Ciechanover A, et al: Ubiquitin ligase activity and tyrosine phosphorylation underlie suppression of growth factor signaling by c-Cbl/Sli-1. Mol Cell 4: 1029-1040, 1999.

34. Haglund K, Sigismund S, Polo S, Szymkiewicz I, Di Fiore PP and Dikic I: Multiple monoubiquitination of RTKs is sufficient for their endocytosis and degradation. Nat Cell Biol 5: 461-466, 2003.

35. Mosesson Y, Shtiegman K, Katz M, Zwang Y, Vereb G, Szollosi J and Yarden Y: Endocytosis of receptor tyrosine kinases is driven by monoubiquitylation, not polyubiquitylation. J Biol Chem 78: 21323-21326, 2003.

36. Pallis AG, Voutsina A, Kalikaki A, Souglakos J, Briasoulis E, Murray S, Koutsopoulos A, Tripaki M, Stathopoulos E, Mavroudis D and Georgoulias V: 'Classical' but not 'other' mutations of EGFR kinase domain are associated with clinical outcome in gefitinib-treated patients with non-small cell lung cancer. Br J Cancer 97: 1560-1566, 2007. 